\title{
HUBUNGAN UMUR DAN PARITAS IBU DENGAN KEJADIAN RETENSIO PLASENTA
}

\author{
Intiyaswati*Puput Pramesti** \\ 1,2Stikes William Booth, Jl.Cimanuk no. 20 Surabaya \\ Email : intiyaswati21@gmail.com
}

\begin{abstract}
ABSTRAK
Pendahuluan : Angka kejadian retensio plasenta di PMB Sari Surabaya selama tiga periode pada tahun 2019-2020 cenderung meningkat yaitu 2,83\% - 4,19\%, dimana retensio plasenta dapat menyebabkan perdarahan postpartum primer yang merupakan penyebab utama kematian ibu. Penelitian ini bertujuan untuk mengetahui Hubungan antara Umur dan Paritas dengan Kejadian Retensio Plasenta di PMB Sari Surabaya. Metode : Pada penelitian ini menggunakan metode Analitik dan desain Cross sectional. Populasi sebanyak 568 orang dengan sampel sebanyak 58 orang. Pengumpulan data menggunakan data sekunder yaitu buku register persalinan di PMB Sari Surabaya. Data diolah, disajikan dengan Tabulasi Frekuensi dan Silang kemudian dianalisa dengan Uji ChiSquare. Hasil : Hasil penelitian didapatkan umur ibu bersalin mayoritas 20-35 tahun sebanyak 40 orang $(68,9 \%)$ dan paritas mayoritas primipara sebanyak 38 orang $(65,5 \%)$. Sedangkan ibu bersalin yang mengalami retensio plasenta sebanyak 19 orang $(32,8 \%)$. Hasil analisa data untuk umur dengan Uji Chi Square diperoleh $\chi^{2}$ hitung 13,6 dan $\chi^{2}$ tabel 3,84 jadi $\chi^{2}$ hitung $>\chi^{2}$ tabel maka Ho ditolak. Untuk paritas dengan Uji Chi Square diperoleh $\chi^{2}$ hitung 6,7 dan $\chi^{2}$ tabel 3,84 jadi $\chi^{2}$ hitung $>\chi^{2}$ tabel maka Ho ditolak. Diskusi :Para petugas kesehatan khususnya bidan hendaknya mampu menangani retensio plasenta secara cepat dan tepat sehingga angka kejadian perdarahan postpartum primer dan angka kematian ibu dapat diminimalkan.
\end{abstract}

Kata Kunci : Umur, Paritas, Retensio Plasenta.

\section{ABSTRACT}

Introduction : The incidence of retained placenta at PMB Sari Surabaya for three periods in 2019-2020 tends to increase, namely 2.83\% - 4.19\%, where retained placenta can cause primary postpartum hemorrhage which is the main cause of maternal death. This study aims to determine the relationship between age and parity with the incidence of retained placenta in PMB Sari Surabaya. Methods : In this study using analytical methods and cross sectional design. The population is 568 people with a sample of 58 people. Data collection uses secondary data, namely the birth register book at PMB Sari Surabaya. The data is processed, presented with Frequency and Cross Tabulations and then analyzed by Chi-Square Test. Results : The results of the study showed that the majority of women giving birth were 20-35 years old as many as 40 people (68.9\%) and parity of the majority of primiparas as many as 38 people (65.5\%). Meanwhile, there were 19 women who gave birth who experienced retained placenta (32.8\%). The results of data analysis for age with Chi Square test obtained $\chi^{2}$ count 13.6 and $\chi^{2}$ table 3.84 so $\chi^{2}$ count $>\chi^{2}$ table then Ho is rejected. For parity with Chi Square test obtained $\chi^{2}$ count 6.7 and $\chi^{2}$ table 3.84 so $\chi^{2}$ count $>\chi^{2}$ table then Ho is rejected. Discussion : Health workers, especially midwives, should be able to handle retained placenta quickly and precisely so that the incidence of postpartum hemorrhage primary and maternal mortality rates can be minimized.

Keywords: Age, Parity, Placental Retentio.

\section{PENDAHULUAN}

Persalinan merupakan akhir kehamilan dan dimulainya kehidupan di luar Rahim bagi bayi baru lahir (Bobak, 2005) dimana hal ini merupakan hal yang fisiologis. Namun tidak semua proses persalinan berjalan normal tanpa komplikasi, dan akibat dari komplikasi tersebut adalah kematian ibu bahkan bayi.

Angka kematian ibu (AKI) yang merupakan salah satu indikator terhadap kesehatan sebuah negara saat ini masih sangat tinggi di Indonesia (Depkes RI, 2007). 
Menurut Survei Demografi Kesehatan Indonesia (SDKI) tahun 2009 AKI di Indonesia sebesar 212/100.000 kelahiran hidup. Sementara di Singapura sebesar 3/100.000 kelahiran hidup,di Malaysia 22/100.000 kelahiran hidup, bahkan di Filiphina 85/100.000 kelahiran hidup (Depkes RI, 2007)

Angka kematian ibu untuk wilayah Jawa Timur adalah 168/100.000 kelahiran hidup pada tahun 2006. Pada tahun 2008 angka kematian ibu di Jawa Timur 83,14/100.000 kelahiran hidup dengan penyebab kematian adalah perdarahan $33 \%$, eklamsia/pre eklamsia $25 \%$, penyakit jantung $12 \%$, infeksi $8 \%$, dan lain-lain 22\% (Dinkes, 2011). Berdasarkan data Dinas Kesehatan Jawa Timur, persentasi kematian ibu tahun 2008 sebesar 83,14\%, tahun 2009 sebesar 90,7\%, dan tahun 2010 sebesar 101,4\%. Dari data tersebut kita dapat melihat bahwa angka kematian ibu di Jawa Timur terus meningkat dari tahun 2019-2020. Selama tahun 2019 tercatat sebanyak 627 ibu meninggal di Jawa Timur. Angka kematian ibu tertinggi di Jawa Timur yaitu di Jember, kota Surabaya, dan Kediri

Penyebab utama kematian ibu di Indonesia adalah perdarahan (atonia uteri; 50$60 \%$, sisa plasenta; $23-24 \%$, retensio plasenta; $16-17 \%$, persalinan dengan laserasi jalan lahir; 4-5\% dan kelainan darah ; 0,5-0,8\%). Perdarahan terjadi 10 kali lebih sering pada saat persalinan (Mochtar, 2011).

Salah satu penyebab kematian ibu pada sebagian besar kasus perdarahan dalam masa nifas yang terjadi adalah karena retensio plasenta, sehingga perlu dilakukan upaya penanganan yang baik dan benar yang dapat diwujudkan dengan upaya peningkatan ketrampilan tenaga kesehatan khususnya dalam pertolongan persalinan, peningkatan manajemen Pelayanan Obstetric Neonatal Emergensi Dasar (PONED) dan Pelayanan Obstetric Neonatal Emergensi Komprehensif (PONEK), ketersediaan dan keterjangkauan fasilitas kesehatan yang merupakan prioritas dalam pembangunan sektor kesehatan guna pencapaian target Millenium Development Goal's (MDG's) tersebut.

Tabel 1 Angka Kejadian Retensio Plasenta di PMB Sari Surabaya Tahun 20192020.

\begin{tabular}{|c|c|c|c|}
\hline Tahun & $\begin{array}{l}\sum_{\text {Persalinan }} \\
\end{array}$ & $\begin{array}{l}\text { MRetensio } \\
\text { Plasenta }\end{array}$ & $\%$ \\
\hline 2010 & 460 & 13 & 2,83 \\
\hline 2011 & 421 & 16 & 3,80 \\
\hline 2012 & 668 & 28 & 4,19 \\
\hline
\end{tabular}

Sumber : Register Persalinan PMB Sari Surabaya Tahun 2019-2020.

Dari tabel 1 dapat disimpulkan bahwa jumlah ibu bersalin yang mengalami retensio plasenta di PMB Sari Surabaya mengalami peningkatan pada tahun 2019-2020 yaitu dari 2,83\%-4,19\% . Dari jumlah kejadian retensio plasenta di PMB Sari Surabaya tahun 20192020 diklasifikasikan dalam kelompok umur dan paritas yang dapat dilihat pada tabel 1.2 dan 1.3 berikut ini:

Tabel 2 Angka Kejadian Retensio Plasenta Berdasarkan Kelompok Umur di PMB Sari Surabaya Tahun 2019-2020.

\begin{tabular}{|c|c|c|c|c|c|c|c|}
\hline \multirow[t]{2}{*}{ Tahun } & \multirow{2}{*}{$\sum_{\text {?etensio }}$} & \multicolumn{6}{|c|}{ Umur (Tahun) } \\
\hline & & $<20$ & $b$ & $20-$ & $\%$ & $>35$ & $\%$ \\
\hline 2010 & 13 & 0 & 0 & 4 & 30,8 & 9 & 69,2 \\
\hline 2011 & 16 & 0 & 0 & 5 & 31,3 & 11 & 68,7 \\
\hline 2012 & 28 & 0 & 0 & 7 & 25 & 21 & 75 \\
\hline
\end{tabular}

Sumber : Register Persalinan PMB Sari Surabaya Tahun 2019-2020.

Dari tabel 2 dapat disimpulkan bahwa kejadian retensio plasenta pada tahun 20192020 di PMB Sari Surabaya mayoritas terjadi pada wanita dengan umur lebih dari 35 tahun.

Tabel 3 Angka Kejadian Retensio Plasenta Berdasarkan Paritas di PMB Sari Surabaya Tahun 2019-2020.

\begin{tabular}{lcccccc}
\hline Tah & \multicolumn{6}{c}{ Paritas } \\
\cline { 2 - 7 } & $\begin{array}{l}\text { Primip } \\
\text { ara }\end{array}$ & $\%$ & $\begin{array}{l}\text { Mult } \\
\text { ipara }\end{array}$ & $\%$ & $\begin{array}{l}\text { Grandemu } \\
\text { ltipara }\end{array}$ & $\%$ \\
201 & 2 & 15,4 & 7 & 53,8 & 4 & 30 \\
0 & & & & & & 8 \\
201 & 1 & 6,25 & 11 & 68,7 & 4 & 25 \\
1 & & & & 5 & & \\
201 & 2 & 7,1 & 19 & 67,9 & 7 & 25 \\
2 & & & & & & \\
\hline
\end{tabular}

Sumber : Register Persalinan PMB Sari Surabaya Tahun 2019-2020.

Berdasarkan tabel 3 dapat disimpulkan bahwa retensio plasenta Lebih banyak terjadi pada ibu multipara dan grandemultipara.

Retensio plasenta disebabkan oleh berbagai faktor yaitu faktor maternal dan faktor uterus. Faktor maternal antara lain: gravida berusia lanjut, faktor uterus: bekas sectio caesarea, bekas kuretase, riwayat 
retensio plasenta pada persalinan terdahulu, riwayat endometritis. Retensio plasenta juga disebabkan oleh multiparitas dan faktor plasenta yaitu implantasi plasenta seperti plasenta adhesiva, plasenta akreta, plasenta inkreta dan plasenta perkreta (Manuaba, 2010).

Umur yang terlalu tua serta paritas tinggi dapat menjadi predisposisi terjadinya retensio plasenta. Hal ini dikarenakan umur ibu yang terlalu tua mempengaruhi kerja rahim dimana sering terjadi kekakuan jaringan yang berakibat miometrium tidak dapat berkontraksi dan retraksi dengan maksimal (Rochjati, 2011). Sedangkan pada paritas tinggi, uterus kehilangan elastisitasnya sehingga miometrium tidak dapat berkontraksi dan retraksi secara maksimal sehingga menimbulkan terjadinya atonia uteri. Hal ini menyebabkan plasenta tidak bisa terlepas dari tempat implantasinya ataukah plasenta sudah lepas tetapi belum keluar karena atonia uteri( Sofian, 2011).

Retensio plasenta merupakan komplikasi persalinan yang cukup serius, karena dalam waktu singkat ibu bisa mengalami perdarahan post partum dan hal ini juga dapat menyebabkan ibu jatuh dalam keadaan syok, anemis, infeksi, bahkan kematian.

Upaya yang dilakukan dalam menurunkan angka kejadian retensio plasenta antara lain dengan meningkatkan penerimaan keluarga berencana sehingga memperkecil terjadinya retensio plasenta, meningkatkan penerimaan pertolongan persalinan oleh tenaga kesehatan yang terlatih, pada waktu melakukan pertolongan persalinan kala III tidak diperkenankan untuk melakukan masase dengan tujuan mempercepat persalinan plasenta. Masase yang tidak tepat waktu dapat mengacaukan kontraksi otot rahim dan mengganggu pelepasan plasenta(Manuaba, 2010). Selain itu juga perbaikan pelayanan gawat darurat, memberikan penyuluhan tentang resiko tinggi ibu hamil pada masyarakat ( Saifuddin, 2009), serta peningkatan keterampilan tenaga kesehatan (bidan) dalam melakukan asuhan persalinan normal (APN, 2007).

Berdasarkan masih tingginya angka kejadian retensio plasenta dari tahun 20192020 sebesar $2,83 \%$ menjadi $4,19 \%$, maka dipandang perlu dilakukan penelitian tentang

hubungan antara umur dan paritas ibu dengan kejadian retensio plasenta.

\section{METODE PENELITIAN}

Penelitian survey cross sectional ini dilaksanakan pada Okrober sampai penelitian bulan Desember 2019 Semua ibu bersalin di PMB Sari Surabaya bulan Januari - September tahun 2013 sebesar 568. Sampel yang diambil dengan teknik Systematic Random Sampling sebagian ibu bersalin di PMB Sari Surabaya bulan Oktober 2019 - Februari tahun 2020 sebesar 58 orang.

Variabel penelitian adalahkejadian retensio plasentasertaumur dan paritas ibu bersalin. Data dikumpulkan dari buku register persalinan PMB Sari Surabaya Bulan Oktober 2019 - Februari tahun 2020.. Selanjutnya data dianalisis dengan uji Chi-Square dan untuk kepentingan uji statistik maka skala ordinal direduksi menjadi skala nominal.

\section{HASIL PENELITIAN}

Umur Ibu Bersalin

Tabel 4 Frekuensi Umur Ibu Bersalin di PMB Sari Surabaya Tahun 2019-2020

\begin{tabular}{ccc}
\hline $\begin{array}{c}\text { Umur } \\
\text { (tahun) }\end{array}$ & Frekuensi & Persentase (\%) \\
\hline$<20$ dan $>35$ & 18 & 31,1 \\
$20-35$ & 40 & 68,9 \\
Jumlah & 58 & 100 \\
\hline Sumber : Register Persalinan PMB Sari Surabaya Tahun \\
2013 \\
Tabel & 4dapat & disimpulkan bahwa
\end{tabular}

bahwa ibu bersalin di Puskesmas Jagir mayoritas umur 20-35 tahun sebanyak 40 orang $(68,9 \%)$.

\section{Paritas}

Tabel 5 Frekuensi Paritas Ibu Bersalin di PMB Sari Surabaya Tahun 2019

\begin{tabular}{ccc}
\hline Paritas & Frekuensi & $\begin{array}{c}\text { Persentase } \\
(\%)\end{array}$ \\
\hline Primipara & 38 & 65,5 \\
Multipara dan & 20 & 34,5 \\
Grandemultipara & & \\
Jumlah & 58 & 100 \\
\hline Sumber : Data yang Diolah Peneliti \\
Tabel 5 dapat disimpulkan bahwa \\
paritas ibu bersalin di PMB Sari Surabaya \\
mayoritas primipara yaitu sebanyak 38 orang \\
$(65,5 \%)$.
\end{tabular}


Kejadian BBLR di Rumah Sakit Pusura Surabaya Tahun 2019-2020

\section{PEMBAHASAN}

Retensio plasenta merupakan komplikasi dalam persalinan yang menduduki posisi ketiga sebagai penyebab perdarahan postpartum primer dimana perdarahan postpartum primer merupakan prioritas pertama dalam kematian ibu bersalin di Indonesia. Oleh karena itu memerlukan perhatian yang serius dan adekuat.

Dalam pembahasan ini, penulis membandingkan 2 hal yaitu umur dan paritas ibu bersalin dengan kejadian retensio plasenta.

Umur adalah usia individu yang terhitung mulai saat dilahirkan sampai saat berulang tahun (Nursalam, 2001). Menurut Saifuddin, umur dibagi menjadi 3 yaitu umur $<20$ tahun, umur 20-35 tahun dan umur >35 tahun. Walaupun umur 20-35 tahun dikatakan sebagai kurun waktu reproduksi sehat tetapi tidak menutup kemungkinan terjadi komplikasi retensio plasenta saat melahirkan, sekalipun tidak setinggi resiko pada saat umur $<20$ tahun dan $>35$ tahun.

Berdasarkan hasil penelitian dari 58 orang ibu bersalin di PMB Sari Surabaya tahun 2019-2020 mayoritas adalah umur 20-35 dibandingkan umur $<20$ dan $>35$ tahun. Sedangkan dari 19 orang ibu bersalin yang mengalami retensio plasenta mayoritas pada umur $<20$ tahun dan $>35$ tahun dibandingkan umur 20-35 tahun.

Hal ini disebabkan pada umur $<20$ tahun organ reproduksi belum dapat berfungsi dengan baik, myometrium tidak bisa berkontraksi dan retraksi dengan maksimal maka proses pelepasan plasenta dari tempat implantasinya juga terganggu yang akhirnya menyebabkan retensio plasenta. Sedangkan untuk umur >35 tahun sering mengalami kekakuan jaringan sehingga miometrium juga tidak dapat bekerja dengan maksimal.

Dilihat dari analisis data dengan menggunakan Uji Chi-Square didapatkan ada hubungan antara umur ibu bersalin dengan kejadian retensio plasenta.

Paritas adalah keadaan seorang wanita sehubungan dengan kelahiran anak yang dapat hidup (Dorland, 2002). Menurut Saifuddin, paritas yang berpotensi mengalami retensio plasenta adalah pada multipara dan grandemultipara. Pada multipara terjadi kemunduran dan cacat pada endometrium yang mengakibatkan terjadinya fibrosis pada bekas implantasi plasenta pada persalinan sebelumnya, sehingga vaskularisasi menjadi berkurang. Untuk memenuhi kebutuhan nutrisi janin, plasenta akan mengadakan perluasan implantasi dan vili khorialis akan menembus dinding uterus lebih dalam lagi sehingga akan terjadi plasenta adhesiva sampai perkreta. Selain itu juga, pada multipara dan grandemultipara terjadi penurunan elastisitas uterus sehingga miometrium tidak dapat berkontraksi dan beretraksi dengan maksimal yang mengakibatkan terjadinya retensio plasenta.

Berdasarkan hasil penelitian yang didapatkan dari 58 orang ibu bersalin di PMB Sari Surabaya Tahun 2019-2020 mayoritas paritasnya adalah primipara dibandingkan multipara dan grandemultipara. Sedangkanyang mengalami retensio plasenta mayoritas pada multipara dan grandemultipara dibandingkan primipara. Hal ini disebabkan karena rahim sering terjadi terjadi peregangan sehingga kehilangan elastisitasnya yang kemudian berdampak miometrium tidak dapat berkontraksi dan retraksi dengan maksimal.

Dilihat dari analisis data dengan menggunakan Uji Chi-Square didapatkan ada hubungan antara paritas ibu bersalin dengan kejadian retensio plasenta.

Melihat hasil penelitian di atas dapat disimpulkana bahwa umur memegang peranan penting dalam menjalani proses reproduksi sehat. Walaupun demikian, dalam umur reproduksi sehat yaitu umur 20-35 tahun, dimana dikatakan bahwa pada umur ini baik untuk bereproduksi namun tidak menutup kemungkinan terjadi komplikasi retensio plasenta saat persalinan.Begitu halnya dengan paritas, paritas yang aman dalam proses reproduksi adalah primipara sedangkan multipara dan grandemultipara beresiko terjadi retensio plasenta.

Dari hasil penelitian di PMB Sari Surabaya, tidak ditemukan kesenjangan antara teori tentang hubungan antara umur dan paritas ibu bersalin dengan kejadian retensio plasenta dimana kejadian retensio plasenta mayoritas terjadi pada ibu bersalin umur $<20$ tahun dan $>35$ tahun dan paritas multipara dan grandemultipara. Oleh sebab itu diperlukan perencanaan kehamilan dan persalinan. Dalam hal ini peran bidan dalam menangani 
kehamilan resiko tinggi hendaknya pertolongan persalinan dilakukan di rumah sakit. Untuk menentukan kehamilan resiko tinggi mengacu pada Kartu Skala Poedji Rochjati (KSPR) sedangkan untuk pencegahan terjadinya komplikasi retensio plasenta dilakukan Ante Natal Care (ANC) yang komprehensif dan berkualitas dan pertolongan persalinan dilakukan sesuai standar Asuhan Persalinan Normal (APN) dengan harapan angka kematian ibu diminimalkan.

\section{SIMPULAN DAN SARAN Simpulan}

Berdasarkan hasil penelitian dapat disimpulkan bahwa ada hubungan antara umur dan paritas dengan kejadian retensio plasenta.

Saran

Mengingat masih tingginya kejadian Retensio Plasenta maka diharapkan tenaga kesehatan khususnya bidan meningkatkan mutu pelayanan dalam penatalaksanaan retensio plasenta sesuai dengan prosedur dan tetap memperhatikan prinsip asuhan sayang ibu. Petugas hendaknya dapat memberikan KIE kepada pasangan usia subur bagaimana mengatur dan merencakanan kehamilan.

\section{KEPUSTAKAAN}

Bobak, I., 2004. Perawatan Maternitas. Jakarta: EGC.

Budijanto, D., 2012. Metodologi Penelitian. Surabaya: Unit Penelitian dan Pengabdian Masyarakat Politeknik Kesehatan Surabaya.

Depkes RI., 2007. Profil Kesehatan Indonesia 2007. Tersedia di http://www.library.usu.ac.id (Diakses tanggal 30 April 2013)

Dinkes., 2011. Profil Kesehatan Provinsi Jawa Timur. Tersedia di http://www.dinkesjatim.go.id Diakses tanggal 30 April 2013).

Fraser, D., 2009. Myles Buku Ajar Kebidanan Edisi 14. Jakarta: EGC.

Hidayat, AA., 2010. Metodologi Penelitian Kebidanan dan Teknik Analisis Data. Jakarta: Salemba Medika.

Joeharno., 2007. Faktor-faktor Penyebab Retensio Plasenta. Tersedia di : dokbid.com (Diakses tanggal $16 \mathrm{Mei}$ 2013).
Manuaba, IA., 2010. Ilmu Kebidanan, Penyakit Kandungan dan $K B$. Jakarta: EGC.

Nazir, M., 2009.Metodologi Penelitian. Bogor: Ghalia Indonesia

Notoatmodjo, S., 2007.Promosi Kesehatan dan Ilmu Perilaku. Jakarta: Rineka Cipta

Notoatmodjo, S. 2010. Metodologi Penelitian Kesehatan. Jakarta: Rineka Cipta

Nursalam., 2011. Konsep dan Penerapan Metodologi Penelitian Ilmu Keperawatan. Jakarta: Salemba Medika

Rochjati, P., 2011. Skrining Antenatal Pada Ibu Hamil. Surabaya: Pusat Penerbit dan Percetakan UNAIR.

Saifuddin, AB., 2006. Pelayanan Kesehatan Maternal dan Neonatal. Jakarta: EGC

Saifuddin, AB., 2009. Ilmu Kebidanan. Jakarta: Yayasan Bina Pustaka Sarwono Prawirohardjo.

Sofian, A., 2011. Sinopsis ObstetriJilid I. Jakarta: EGC.

Sumarah.,2008. Perawatan Ibu Bersalin (Asuhan Kebidanan Pada Ibu Bersalin). Yogyakarta: Fitramaya. 